http://dx.doi.org/10.4314/ajid.v9i2.8

SEROPREVALENCE STUDY OF HTLV-1 and 2 IN PROSPECTIVE BLOOD DONORS AND PREGNANT WOMEN IN PORT HARCOURT, NIGERIA.

\title{
Iyalla Caroline ${ }^{1 *}$, Ejele Adebayo Oseikhuemen ${ }^{2}$, Okoh, Dorathy Adaunwo ${ }^{1}$, Igbigbi, Elizabeth ${ }^{2}$.
}

${ }^{1}$ Haematology unit, Department of Pathology, Braithwaite Memorial Specialist Hospital, UPTH, Port Harcourt, ${ }^{2}$ Department of Haematology, Blood transfusion and Immunology, Faculty of Basic Medical Sciences, College of Health Sciences, University of Port Harcourt, Nigeria.

*E-mail: carol.ivalla@gmail.com

\begin{abstract}
Background: Infection with Human T-cell Lymphotropic virus type 1 and 2 (HTLV-1/2) is a global epidemic. Nigeria is in the endemic region of HTLV $1 / 2$ infections. The diseases caused by these viruses are incurable and life-threatening. There is no data yet on the seroprevalence of these viruses in Port Harcourt, Nigeria. We determined the seroprevalence of HTLV-1/2 by identifying antibodies to the virus in Nigerians resident in Port Harcourt.

Methods and Materials: This was a cross-sectional study we carried out on a total of 360 participants (139 potential blood donors and 221 pregnant women) at the Braithwaite Memorial Specialist Hospital (BMSH) and University of Port Harcourt Teaching Hospital (UPTH). The participants were also given self -administered questionnaires. We screened for antibodies to HTLV-1 and 2 in the sera of the participants using Enzyme Linked Immunoabsorbent assay (ELISA). We also screened for antibodies to Human Immunodeficiency Virus types 1 and 2 (HIV-1/2) using qualitative immunoassay determine test strips.

Results: Two (1.4\%) of blood donors were positive for HTLV, both were males and $1(0.8)$ was within the 25-34 years age group while the other was in the 35-44years age group. There was an association between Sexually transmitted Diseases (STD) and previous blood transfusion with HTLV positivity. No pregnant women tested positive to HTLV. There were no cases of co-infection of HIV with HTLV.

Conclusion: The results suggest low prevalence of HTLV in blood donors and pregnant women in Port Harcourt.
\end{abstract}

Key words: HTLV-1/2, Seroprevalence, Blood donors, pregnant women, HIV, Co-infection, risk factors.

\section{Introduction}

First discovered in 1979 and published in the 1980's, the Human T-cell Lymphotropic virus types 1 and 2 (HTLV-1/2) are RNA viruses (Poiesz et al., 1980). HTLV-1 causes a T-cell proliferation with persistent infection; it can induce malignancy in an infected human, and has been linked to the Adult Tcell leukaemia/lymphoma (ATL) (Yoshida et al., 1982; Yamaguchi and Watanabe, 2002). It can also lead to a neurologic disorder called tropical spastic paraparesis (TSP) or HTLV-associated myelopathies (HAMS) (Nakamura et al., 1989; Jacobsons et al., 1988). HTLV-2, however, has not been linked to any specific disease entity except for a few cases of cutaneous lymphoma in patients co-infected with HIV (Roucoux and Murphy, 2004).

Infection with HTLV is now a global epidemic; affecting 10 to 20 million people worldwide (Proietti et al., 2005). It is endemic in parts of Southern Japan, Central and West Africa, the Caribbean, the Middle East and Melanesia (Verdonk et al., 2007; Vrielink and Reesink, 2004), with overall prevalence of 5 $10 \%$ (Verdonk et al., 2007). Most carriers are asymptomatic. HTLV-1/2 are transmitted sexually (Roucoux et al., 2005), through blood transfusion (Manns et al., 1992), from mother to child (Ishak et al., 2001) and by intravenous drug use (Etzel et al., 2001). There is possibly $40-60 \%$ sero-conversion within 51 days following an infected blood transfusion (Manns et al., 1992). Approximately 5-10\% of HTLV-1 infected individuals develop either ATL or HAMS/TSP (Barmak et al., 2003).

Mandatory testing of potential blood donors is being practiced in United States of America and about 22 European countries including France, Netherlands, Romania, Norway, Finland and United Kingdom (Laperche et al., 2009). Screening of blood donors is also done in Japan (Inaba et al., 1999) and Brazil (Soares et al., 2003). Nigeria as a country in West Africa is within the endemic region of HTLV -1/ 2 infection. The diseases caused by these viruses are incurable and life-threatening. Recently, there has been an increased demand for blood and its products. Blood donors are not routinely screened for HTLV$1 / 2$ in Nigeria.

Several studies have been done in other countries and a few cities in the South- Western part of Nigeria on the seroprevalence of HTLV-1/ 2. However, there is no data on the seroprevalence of these viruses in Port Harcourt, a cosmopolitan city and capital of Rivers State within the South-South region of Nigeria. We carried out this study to determine the seroprevalence of HTLV-1 / 2 antibodies in Port Harcourt. The results obtained from this study will contribute to the existing data and body of knowledge on the prevalence of HTLV -1/2, and to the safety of blood transfusion practice in Nigeria, especially in the Niger Delta region.

\section{Materials and Methods Study design and subjects}

The study design is cross-sectional and was conducted on two categories of people. These were normal healthy adult volunteers at the blood bank of the University of Port Harcourt Teaching Hospital (UPTH) and Braithwaite Memorial Specialist Hospital (BMSH), and Pregnant women attending antenatal clinic in UPTH and BMSH. A total of 360 participants were recruited into the study, 139 blood donors and 221 pregnant women. Written consent was obtained from each participant and a questionnaire was administered. The questionnaires were structured to obtain information such as bio data, educational status and possible risk factors which are associated with HTLV transmission.

\section{Specimen collection and preparation}

Venous blood was collected with a $5 \mathrm{ml}$ syringe from every participant who gave consent to participate in the study, and put in tubes without anticoagulant. The samples were separated within $6 \mathrm{hrs}$ and the serum put in plain bottles. The samples were stored at $-20^{\circ} \mathrm{C}$ until ready for processing. 


\section{Detection of antibodies to HTLV-1/ 2}

The samples were analysed in batches for antibodies to HTLV-1 and 2 using the Enzyme linked immune-absorbent assay (ELISA) technique. ELISA kits used were from the Diagnostics Automation Incorporated, 23961 Craftsman Rd, Calabasas, CA 91302, United States. Reference number: 8196-12 and Lot numbers: T20120502 and T20110502. The manufacturer's instructions were strictly followed.

\section{Detection of antibodies to HIV}

Sera from subjects were also tested for antibodies to HIV-1/2 by Qualitative immunoassays determine test strips from Alere Medical Company limited, Japan with Reference number 7D2343 and Lot number 45015K100.

\section{Statistical analysis}

The data obtained was entered into excel spread sheet and analysed with the Epi-Info Ver.6.04d statistical package. Chi-square and Fischer's exact tests were used for statistical significance between variables.

\section{Results}

A total of 360 participants were recruited for the study, this consisted of 221 pregnant women and 139 blood donors. Of the blood donors, 123 were males $(88.4 \%)$ while 16 were females (11.6\%). Of the blood donors screened, 2 (1.4\%) had antibodies to HTLV-1/2 while 137 (98.6\%) were negative for the presence of the antibodies. None of the pregnant women tested were positive to HTLV-1/2 antibodies. Antibodies to HIV-1/2 were detected in 11 ( $7.9 \%$ ) of blood donors while the rest $(92.1 \%)$ were negative for the antibodies. Of the pregnant women, $25(11.7 \%)$ were positive to HIV-1/2 while 208 (94.1\%) were negative. There was no case of co-infection of HIV with HTLV. The overall prevalence rate is therefore $0.5 \%$.

The age prevalence of HTLV-1/2 among blood donors was $1(0.8 \%)$ for 25-34 years age group, p value (0.672) was not significant and $1(0.8 \%)$ for the 35 44 years age group with $\mathrm{p}$ value of 0.573 which was also not significant. The sex prevalence was $2(1.4 \%)$ for males ( $\mathrm{p}=0.641$ is not significant) and 0 $(0.0 \%)$ for female $(\mathrm{p}=0.802)$. One $(0.8 \%)$ of those that were positive for HTLV had a history of blood transfusion, the relative risk (RR) was greater than 1 and the $p$ value (0.07) was not significant. Both sero-positive persons have had more than 1 sexual partners in the last 5 years, the RR is $<1(0.94)$ and the $p$ value (0.233) is not significant. The 2 sero-positive persons for HTLV also had a history of previous STD, the RR was> 1(1.22) and the $\mathrm{p}$ value (0.01) was significant. None of the sero-positive persons had a history of IDU, RR was $<1(0.98)$ and the p value $(0.950)$ was not significant.

Table I: Age and Sex prevalence of HTLV-1/2 infection in blood donors

\begin{tabular}{|c|c|c|c|}
\hline & HTLV & & \\
\hline AGE GROUP & $\begin{array}{l}\text { Positive } \\
\qquad \begin{array}{c}\mathrm{n}=2) \\
\mathrm{n}(\%)\end{array}\end{array}$ & $\begin{array}{l}\text { Negative } \\
\qquad \begin{array}{r}(\mathrm{n}=130) \\
\mathrm{n}(\%)\end{array}\end{array}$ & \\
\hline $18-24$ & $0(0.0)$ & $18(13.6)$ & 0.774 \\
\hline $25-34$ & $1(0.8)$ & $58(43.9)$ & 0.672 \\
\hline $35-44$ & $1(0.8)$ & $42(31.8)$ & 0.573 \\
\hline $45-54$ & $0(0.0)$ & $8(6.1)$ & 0.889 \\
\hline $55-64$ & $0(0.0)$ & $4(3.0)$ & 0.942 \\
\hline SEX & $\begin{array}{l}\text { Positive } \\
\qquad \begin{array}{c}\mathrm{n}=2) \\
\mathrm{n}(\%)\end{array}\end{array}$ & $\begin{array}{l}\text { Negative } \\
\qquad(\mathrm{n}=137) \\
\mathrm{n}(\%)\end{array}$ & \\
\hline Male & $2(1.4)$ & $121(88.4)$ & 0.641 \\
\hline Female & $0(0.0)$ & $16(11.6)$ & 0.802 \\
\hline
\end{tabular}

\section{Discussion}

Infection with HTLV-1/2 affects 10-20 million people worldwide (Roucoux and Murphy, 2004), with an overall prevalence of 5-10\% (Verdonk et al., 2007), though rates as high as $15 \%$ have been reported (Proietti et al., 2005).However, HTLV is said to be confined to specific geographical areas, and SubSaharan Africa is in that endemic belt of HTLV, with a stable incidence and high prevalence (Van Tienen et al., 2010). Overall prevalence rate in Nigeria 
http://dx.doi.org/10.4314/ajid.v9i2.8

was documented by Olaleye et al in 1994 to be $5.6 \%$ (Olaleye et al., 1994). But this study, however, recorded a much lower rate of $0.5 \%$ which is similar to values obtained in non-endemic areas (Tajima and Yinuma, 1992). The difference may be due to the population groups used in the Olaleye study which included high risk groups such as patients with STD and Commercial Sex Workers (CSWs).

Table 2: HTLV - Associated Risk factors in blood donors positive for HTLV

\begin{tabular}{|c|c|c|c|c|}
\hline \multirow{2}{*}{$\begin{array}{l}\text { CHARACTERISTICS } \\
\text { OF SUBJECTS }\end{array}$} & \multicolumn{2}{|c|}{ HTLV } & \multirow{2}{*}{$\begin{array}{l}\text { RELATIVE RISK } \\
\text { (RR) } \\
(95 \% \mathrm{CL}) \\
\end{array}$} & \multirow{2}{*}{ p- value* } \\
\hline & $\begin{array}{l}\text { Positive } \\
\mathrm{n}(\%)\end{array}$ & $\begin{array}{c}\text { Negative } \\
\mathrm{n}(\%)\end{array}$ & & \\
\hline \multicolumn{5}{|c|}{ Previous blood Transfusion } \\
\hline $\begin{array}{l}\text { YES } \\
\text { NO }\end{array}$ & $\begin{array}{l}1(0.8) \\
1(0.8)\end{array}$ & $\begin{array}{l}4(3.0) \\
127(95.5)\end{array}$ & $\begin{array}{c}1.24 \\
(0.80-1.92)\end{array}$ & 0.07 \\
\hline \multicolumn{5}{|l|}{ No. of Sexual Partners } \\
\hline $\begin{array}{l}\text { More than one } \\
\text { One }\end{array}$ & $\begin{array}{l}2(2.3) \\
0(0.0)\end{array}$ & $\begin{array}{l}29(33.0) \\
57(64.8)\end{array}$ & $\begin{array}{c}0.94 \\
(0.85-1.03) \\
\end{array}$ & 0.233 \\
\hline \multicolumn{5}{|c|}{ Intravenous Drug Use (IDU) } \\
\hline $\begin{array}{l}\text { YES } \\
\text { NO }\end{array}$ & $\begin{array}{c}0(0.0) \\
2(1.7)\end{array}$ & $\begin{array}{c}3(2.5) \\
115(95.8)\end{array}$ & $\begin{array}{c}0.98 \\
(0.96-1.01)\end{array}$ & 0.950 \\
\hline \multicolumn{5}{|c|}{ Previous History Of STDs } \\
\hline $\begin{array}{l}\text { YES } \\
\text { NO }\end{array}$ & $\begin{array}{l}2(1.7) \\
0(0.0)\end{array}$ & $\begin{array}{c}9(7.7) \\
106(90.6)\end{array}$ & $\begin{array}{c}1.22 \\
(0.93-1.61)\end{array}$ & $0.01 *$ \\
\hline
\end{tabular}

*p-value significant

Blood product transfusion is an important mode of transmission. Seroprevalence in blood donors in this study is $1.4 \%$, which is similar to rates recorded in endemic areas (1\% and above) (Iwanagi et al., 2009; Ragin et al., 2008). This result is not much different from other prevalence rates obtained from blood donors in other studies from Nigeria. It falls in- between that recorded in Lagos in 1998 which is 3/406(0.7\%) (Analo et al., 1998), and the prevalence rate reported in blood donors in Oshogbo which was 14/372 (3.6\%) in 2008 (Terry et al., 2011). HTLV prevalence increases with age and is commoner in females (Olaleye et al., 1994; Berini et al., 2010; Diop et al., 2006), higher rates are seen in female donors than male donors (Ragin et al., 2008). However, in this study, HTLV positivity was seen in only males (1.4\%).Age-prevalence of HTLV is $1(0.8 \%)$ in $25-34$ years age group and $1(0.8 \%)$ in 35-44years age group. The difference could be the low frequency of female donors (11.6\%) compared to male donors $(88.4 \%)$. This same trend was observed in the Ghanaian blood donors with low frequency of female donors (5.7\%) compared to male donors (94.3\%) (Ampofo et al., 2002).

Pregnant women were also screened in this study because vertical transmission is an important route of transmission of HTLV, mostly via breastfeeding. Therefore refraining from breastfeeding or reducing the period of breast feeding may reduce mother to child transmission. No pregnant woman tested positive for antibodies to HTLV. This is in sharp contrast with seroprevalence rate (16.7\%) documented in Ibadan, Oyo State, which is one of the highest, reported so far (Forbi and Odetunde, 2007). These results were not confirmed by more specific tests, such as Western Blot (WB) and Polymerase Chain Reaction (PCR). An earlier study in pregnant women in Ibadan also gave a high seroprevalence rate (11.5\%) which was confirmed by WB (Olaleye et al., 1995). A possible explanation for the variance in rates between pregnant women in Ibadan and those in this study may be due to the occurrence of HTLV clusters in certain geographical regions. Foci of high prevalence located near areas of low or very low endemicity is a hallmark of HTLV-1/2 epidemiology, though no known explanation for this, but it has been suggested that genetic, environmental and socioeconomic factors may be responsible (Diop et al., 2006; Maucleire et al., 1997). A nationwide study in Gabon involving 5 cities clearly illustrates this; seroprevalence rate of HTLV$1 / 2$ in pregnant women from the South-East region was 5\% while other provinces had from $0 \%$ to $2.1 \%$ prevalence rates (Etenna et al., 2008).

Risk factors associated with HTLV infectivity include multiple sexual partners, a history of STD (Zunt et al., 2002), intravenous drug use (Fukushima et al., 1995) and previous blood transfusion (Manns et al., 1992). Though most of these risk factors were observed in the HTLV seropositive persons in this study, only persons who had previous STDs are more likely to develop possible antibodies to HTLV. Persons who had received blood transfusion are also more likely to develop possible antibodies to HTLV. The results from this study thus further confirm that previous STD increases the risk of acquiring HTLV infections (Rouet et al., 2002). Other studies in Nigeria have shown very high rates of 16.3\%, 35\%, and 50 \%, among STD clinic attendees (Olaleye et al., 1994; Olumide et al., 2008).HTLV-2 has been reported to slow disease progression in persons who are also positive for HIV (Willy et al., 1999), though other reports state otherwise (Eskid et al., 1996). In this study, 11(7.9\%) of the blood donors and 25 (11.7\%) of the pregnant women were positive for antibodies to HIV. However, there was no co-infection of HIV in persons who are positive for HTLV. Other studies have also reported increasing or stable HIV prevalence compared to HTLV, without co-infections (Diop et al., 2006; Ampofo et al., 2002). This confirms that HIV is still the major challenge in this environment, as transmission is on the increase (Frank-Peterside et al., 2012).

Limitations: The assay cannot distinguish between infections with HTLV-1 and HTLV-2. Positive results were not confirmed with methods such as PCR and WB. Despite this limitation, the ELISA kit used is $100 \%$ sensitive and $99.9 \%$ specific.

\section{Acknowledgement}

We acknowledge the efforts of Mr Godwin of BMSH, $\mathrm{PH}$ who assisted in the collection of samples from pregnant in the antenatal clinic. 


\section{References}

1. Ampofo W, Nii-Trebi N, Ansah J, Abe K, Naito H, Aidoo S, Nuvor V, Brandful J, Yamamoto N, Ofori-Adjei D, and Ishikawa K. (2002). Prevalence of bloodborne infectious diseases in blood donors in Ghana. J Clin Microbiol. 40(9):3523-3525.

2. Analo H, Akanmu AS, Akinsete I Njoku OS, and Okany CC. (1998). Seroprevalence study of HTLV-1 and HIV infection in blood donors and patients with lymphoid malignancies in Lagos, Nigeria. Cent Africa J med, 44(5):130-134.

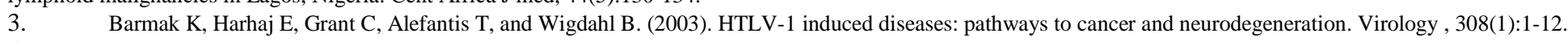

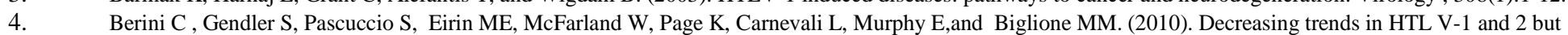

stable HIV -1 infection among replacement donors in Argentina. J Med Virol., 82(5): 873-877.

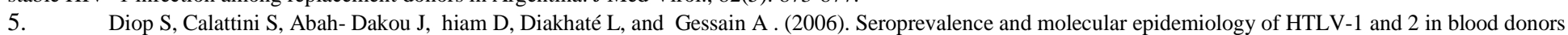
from Dakar, Senegal. J Clin Microbiol., 44(4):1550-1554.

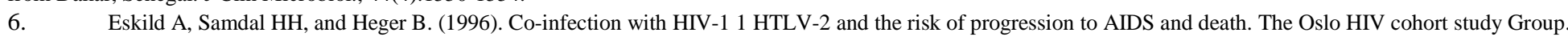
APMIS. , 104:666-72.

7. Etenna SL, Caron M, Besson G, Makuwa M, Gessain A, Mahé A, and Kazanji M. (2008). New insights into prevalence, genetic diversity and proviral load of HTLV-1/2 in pregnant women in Gabon in Equatorial Central Africa. J Clin Microbial., 46 (11): 3607-3614.

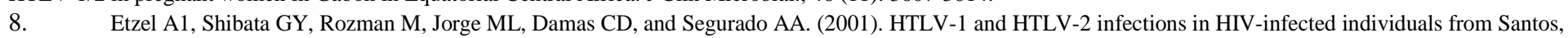
Brazil: seroprevalence and risk factors. J Acquir Immune Defic .Syndr., 26(2):185-90.

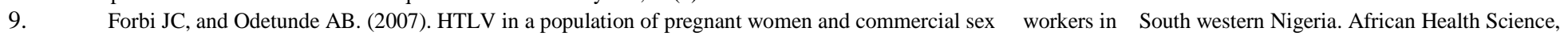
7(3): 129-132.

10. Frank-Peterside N, Okonko IO, Okerentugba PO, and Jaja N. (2012). Detection of HIV 1and 2 antibodies among pregnant women in PH, Rivers state Nigeria. World Applied Sciences Journal, 16(4):589-598.

11. Fukushima Y, Takahashi H, Hall WW, Nakasone T, Nakata S, Song P, Duc DD, Hien B, Quang NX, Trinh TN, Nishioka K, Kitamura K,

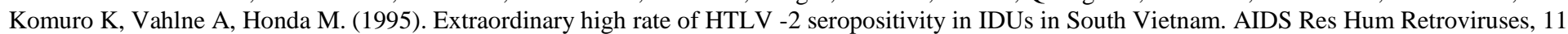
(5):637 -645.

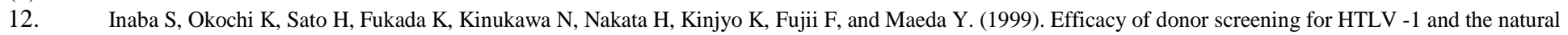
history of transfusion transmitted infection. Transfusion, 39(10):1104-1110.

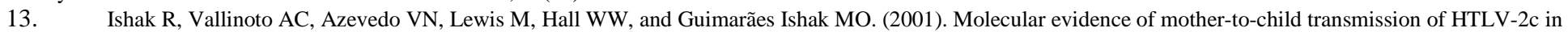
the Kerarao village (Keyapo) in the Amazon region of Brazil. Rev Soc Bras Med Trop.,34(6):519-25.

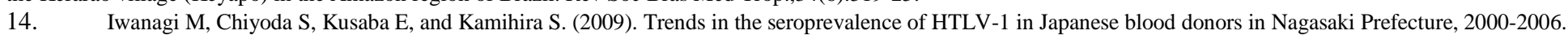
Int J Haem, 90(2):186-190.

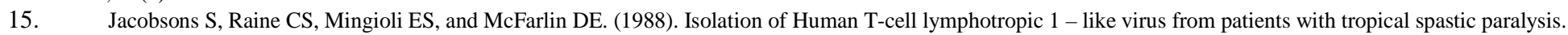
Nature, 331(6156): 540-543.

16. Laperche S, Worms B, and Pillonel J. (2009). Blood safety strategies for HTLV in Europe. Vox Sanguinis , 96(2):104-110.

17. Manns A, Wilks RJ, Murphy EL Haynes G, Figueroa JP, Barnett M, Hanchard B, and Blattner WA. (1992). A prospective study of transmission by blood transfusion of HTLV - 1 and risk factors associated with seroconversion. Int J Cancer, 51:886 - 91.

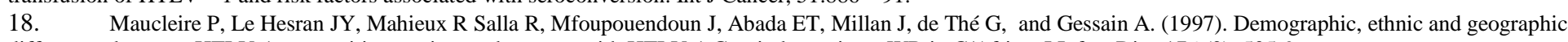
differences between HTLV-1 seropositive carriers and persons with HTLV-1 Gag-indeterminate WB in C/Africa. J Infect Dis., 176 (2): 505-9.

19. Nakamura T1, Tsujihata M, Shirabe S, Matsuo H, Ueki Y, and Nagataki S. (1989). Characterization of HTLV-I in a T-cell line established from a patient with myelopathy. Arch Neurol.,46(1):35-7.

20. Olaleye DO, Bernstein L, Sheng Z, Ekweozor CC, Li XY, Sullivan-Halley J, and Rasheed S. (1994). Type specific immune response to HTLV type 1 and 2 infections in Nigeria. Am J Trop Med Hyg., 50(4): 479-486.

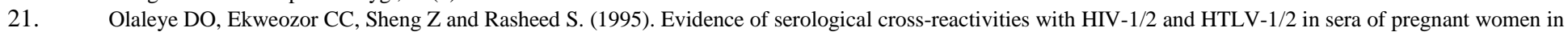
Ibadan, Nigeria. Int J Epidemiol 1995; 24 (1) : 198-203

22. Olumide VM, Dada AJ, Sogbanmu IB, and Aruna GA. (2008). Seroprevalence study of HIV-1, HIV-2 and HTLV-1 among patients at the dermatovenereology clinc of the Lagos State University Teaching Hospital. International Journal of Dermatology, 36(10):741-744.

23. Poiesz BJ, Ruscetti WF, Gazdar AF, Bunn PA, Minna JD, and Gallo RC. (1980). Detection and isolation of type C retrovirus particles from fresh and cultured lymphocytes of a patient with cutaneous T-cell lymphoma. Proc Natl Acad Sci USA., 77 (12): 7415-7419.

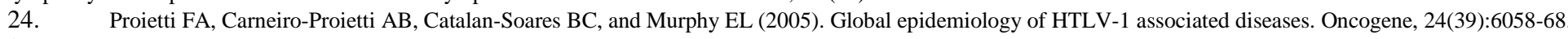

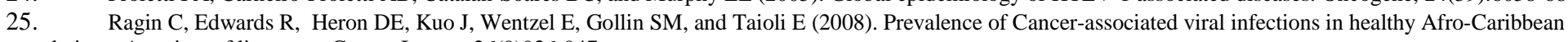
populations: A review of literature. Cancer Invest., 26(9)936-947.

26. Roucoux DF and Murphy EL. (2004). Epidemiology and disease outcomes of Human T-cell lymphotropic virus type II; AIDS Review, 6: 144-54.

27. Roucoux DF, Wang B, Smith D, Nass CC, Smith J, Hutching ST, Newman B,Lee TH, and Chaffets DM.( 2005). A prospective study of sex transmission of HTLV-1/2. J Infect Dis., 191(9):1490-7.

28. Rouet F, Herrmann-Storck C, Courouble G, Deloumeaux J, Madani D, and Strobel M.(2002). A case control study of risk factors associated with HTLV-1 seropositivity in blood donors from Quadeloupe, French West Indies, Vox Sanguinis, 82(2):61-66.

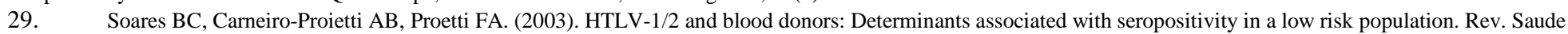
Publica, 37(4): 470-476.

30. Tajima K and Yinuma Y. (1992). Epidemiology of HTLV 1/2 in Japan and the world. Gann Monograph on Cancer Research, 39:129-149.

31. Terry AA, Olusoga OD, Oluremi AS, Okanlawon BM, Uche LM, and Muhibi MA. (2011). Seroprevalence of HTLV-1/2 amongst blood donors in Oshogbo, Nigeria. Sudan J Med Sci., 6(3):177-182.

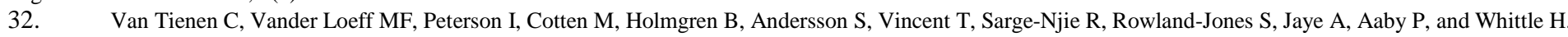
(2010). HTLV-1 in Guinea Bissau: Prevalence, incidence and a continued association with HIV between 1990 and 2007. Retrovirology ,7:50-58.

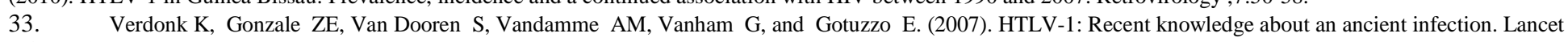
Infect. Dis., 7(4):266-81.

34. Vrielink H and Reesink HW. (2004) HTLV-1/2 prevalence in different geographic locations. Transfus. Med. Rev., 18(1):46-57.

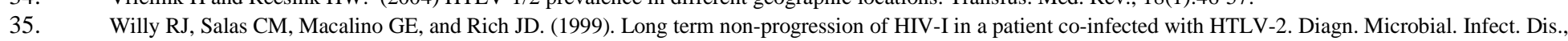
35:269-70.

36. Yamaguchi K and Watanabe T. (2002). Human T-cell lymphotropic virus type 1 and adult T-cell leukaemia in Japan. Int J Haematol., 76(2):240-5.

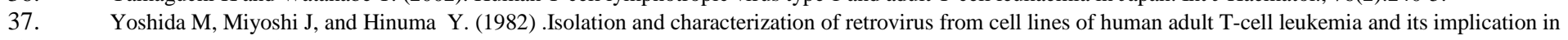
disease. Proc. Natl. Acad. Sc.i USA., 79:2031-2035.

38. Zunt JR, Dezzutti CS, Montano SM, and Holmes KK. (2002). Cervical shedding of HTLV-1 is associated with cervicitis. J Infect Dis, 186(11):1669-1672. 